\title{
2
}

\section{Internal Knowledge Transfer: Professional Development Programmes and Embedding Real World Learning for Full-Time Undergraduates}

David Perrin, Connie Hancock, and Ruth Miller

\section{Introduction}

Negotiated work-based learning (NWBL) frameworks have existed in higher education (HE) in the UK for around 30 years. Thousands of students who are part-time learners at work have gained undergraduate or postgraduate awards through their study on them (Major, 2016; Talbot, 2017). They have involved a particular set of approaches to learning, teaching and assessment for experienced adult professional practitioners, many of which have been distinct from the more traditional pedagogic approaches used for students studying on full-time

Case Studies: Connie Hancock and Ruth Miller

D. Perrin $(\bowtie) \bullet$ C. Hancock

University of Chester, Chester, UK

e-mail: d.perrin@chester.ac.uk

R. Miller

School of Health and Education, Middlesex University, London, UK

(C) The Author(s) 2021

D. A. Morley, M. G. Jamil (eds.), Applied Pedagogies for Higher Education, https://doi.org/10.1007/978-3-030-46951-1_2 


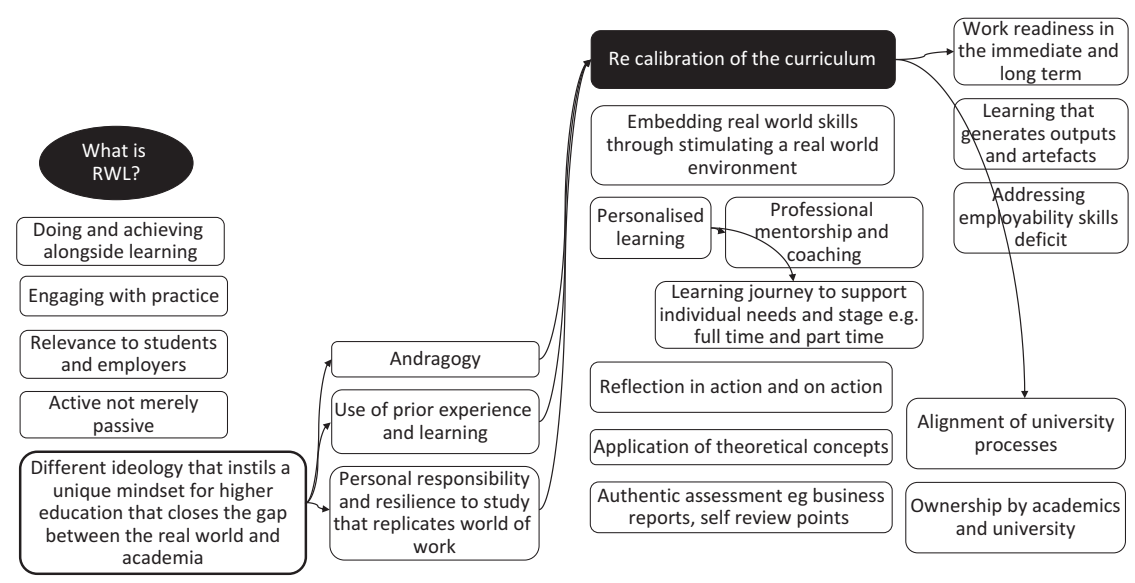

Fig. 2.1 Concept map from the authors

undergraduate programmes (Wall \& Perrin, 2015). Some attempts in recent years have been made to 'leverage' the academic practice deployed on negotiated work-based learning frameworks for other purposes, specifically including the fostering of 'real world learning' for full-time undergraduates. The chapter examines how this leveraging can theoretically happen - and is now also happening in practice - to meet the needs of the economy and wider society for 'work-ready' graduates who are able to apply their learning in real world scenarios as well as critically reflect on this. Key concepts and issues related to this have been identified in the associate concept map (Fig. 2.1).

\section{NWBL: Characteristics}

NWBL involves the creation of a distinct and ragogic learning culture which in many respects is different to 'traditional', didactic higher education. Philosophically, its starting point is that much of the knowledge capital in society exists outside of the academy and resides in workplaces and with the professionals that work in them (Boud \& Symes, 2000; Garnett, Comerford, \& Webb, 2001; Talbot, 2017). In this respect, it draws its inspiration and approaches to learning from outside of the academy in large part too, being focused on the development and 
enhancement of professional knowledge across a range of practice areas. Its progressive view of education is thus associated with the ideas articulated by Dewey (1897) concerning the need to integrate learning and experience.

NWBL does not intrinsically relate to a particular subject discipline or set of disciplines, and is essentially trans-disciplinary in approach (Nicolescu, 2002). Nevertheless, it has common features wherever it is found that make it distinctive and different to more traditional, didactic higher education. In this respect its key features can be identified as being:

- academic recognition for work-based, experiential learning and associated critical reflection on this;

- an andragogic methodology of learning facilitation rather than a pedagogic method of didactic instruction;

- personal and professional skill audits to help inform the choice and planning of development opportunities;

- enabling participants to negotiate key aspects of their learning in ways that reflect their area of practice (including their learning outcomes, methods of assessment and, in some cases, even award titles);

- the intrinsic and conscious embedding of professional skills and capabilities within the curriculum;

- an emphasis on inquiry-based learning, designed to address practical, real-work problems and issues;

- a curriculum that is driven by workplace and professional requirements rather than one pre-configured by the academy according to prevalent academic subject expertise and interests;

- assessment that is work-based and/or work-related, allowing artefacts principally created in and through work to be included for the purposes of academic reward;

- the opportunity to recognise, enhance and build on relevant prior learning (whether certificated or experiential).

Some of these approaches are also used on occasion in more general professional practice programmes and contexts where NWBL frameworks are not necessarily in operation. However, NWBL typically brings together all the features above in a unique way and in this respect exists 
as an exemplar of how learning can be fostered and captured in HE by using innovative, non-traditional methods (if modern $\mathrm{HE}$ teaching, learning and assessment can be seen as a spectrum, NWBL occupies one end of it - arguably the most vivid). Indeed, for similar reasons NWBL frameworks have sometimes been at the forefront of other new initiatives in $\mathrm{HE}$ too such as developments in online and distance learning (Stephenson \& Saxton, 2005). Staff involved in them therefore have a tendency to develop an ideological cohesion around their educational practice that helps foster distinct communities of practice around these approaches to teaching, learning and assessment (Talbot, Perrin, \& Meakin, 2019).

\section{NWBL: Approaches and Practices for 'Real World Learning'}

NWBL is, in essence, based on what has been termed Mode 2 learning rather than Mode 1 learning; that is, it is learning largely generated and held in professional contexts that is typically not aligned to conventional conceptions of academic disciplines (Gibbons et al., 1994). Being mainly experiential and underpinned by reflective practice, it needs expression outside of classroom environments-in real world situations and practices. Only then can the interplay between learning that is taught and learning that is experienced and applied be readily identified and assimilated. The process of critical reflection is able to reveal this process and in doing so deepen and enhance the learning further (Brookfield, 1991).

It would be near impossible to draw up an exhaustive list of what this might entail, but typical examples of the types of knowledge and skill involved from a variety of areas of professional practice would include thinking strategically; applying or adapting learning to new contexts; solving problems so as to create a positive impact; working with other people effectively; communicating professionally; transcending disagreement or conflict; managing and delivering specific tasks and projects to schedule; allocating limited resources effectively. 
Many, if not most, of these attributes are difficult to learn outside of professional contexts-for instance, while a full-time undergraduate student may learn to solve certain types of problems and be confronted by many of these in formal examinations that test them, problem-solving in a real work context is a different matter. It is one thing to solve a mathematical problem but quite another to apply it to an unfamiliar (and possibly changing) context where it becomes just one factor to consider among many others, such as in a situation of resource allocation where supply is limited and demand is uncertain.

Because of this, while traditional learning in undergraduate programmes has value, this value is necessarily limited and constrained. It is only through application and contextualisation in real world situations that it can be truly tested and where its impact can be assessed in the round (Boud \& Symes, 2000). This is where much traditional HE learning is perceived as falling short, even vocational learning fostered by business schools with 'work-ready' graduates very much in mind (Bennis \& O’Toole, 2005; Jackson, 2013).

One way in which more traditional programmes aimed at full-time undergraduates can seek to address this issue is by incorporating methods and approaches developed by staff engaged in NWBL more widely, most productively by rewriting and recalibrating undergraduate programmes where possible to enable real world learning using these methods. There are a number of ways in which this can happen-some fundamental and distinctive, others more subtle.

Some of these methods involve a replication or simulation of real world scenarios and work processes (refer to Chap. 9). But others involve learners engaging at a fundamental level in experiential learning that intrinsically involves the principles and practices of NWBL. For this to happen, learners need to have access to experiential learning opportunities, and this can happen in a variety of ways - through part-time work, through volunteering or through placement opportunities arranged by the university itself (Helyer \& Lee, 2014).

Significant examples of ways this can happen include the following:

1. Introduction of learning agreements: learning agreements (or contracts) can be used to allow learners flexibility in terms of curriculum design. This can exist both at a programme level and at a module level 
(such as where there are negotiated learning opportunities like workbased projects). A particular curriculum may involve a number of predetermined modules but may allow flexibility in terms of other academic credits so as to enable the reward of situated, experiential learning that is negotiated between students, tutors and-where relevant-employers. Learning agreements are designed to empower students to see the workplace as both the site of knowledge generation and the motor-force for designing the 'real world' curriculum and so constitute an important way of facilitating this within HE (Knowles, 1986; Major, 2016; Stephenson \& Laycock, 1993; Talbot, 2017).

2. Use of skills audit and programme planning modules: these are designed to enable learners to develop an awareness of their personal and professional development, their progress in this regard and the opportunities that can be identified for future enhancement and academic reward. In addition, they often encourage students to uncover their preferences and filters through engagement with concepts such as learning styles and personality type, helping students develop a consideration of what Eraut has described as personal knowledge (Eraut, 2010). These processes can then feed into the curriculum design itself to address gaps in skills and knowledge while building on-and enhancing-identified preferences. The results of these processes will typically vary from student to student and will form the basis of the creation of the negotiated curriculum and the personalised learning agreement that captures this in HE (Talbot, 2017; Willis, 2008).

\section{Integration of WBL project modules into the curriculum: many,} if not most, NWBL frameworks use 'shell' or 'template' modules which are characterised by generic aims, learning outcomes and assessment methods, and which can then be customised for specific circumstances by learners. This typically involves work-based projects, or else experiential learning which may cross-cut individual projects but relate to a learning theme (such as presentation skills or effective web design). This approach encourages learners to specifically relate their real world experiential learning to academic process and development, and allows the conferment of academic credit for this (Little \& Brennan, 1996).

4. Systematic integration of reflective practice into the curriculum: there is a huge body of literature on the use of reflective practice for 
educational purposes, and NWBL uses this as a key method for surfacing deep learning and tacit knowledge (Raelin, 2008). This can be embedded not just in work-based experiential learning such as project modules or similar, but also in those instances where students take learning that has sometimes been introduced in more traditional ways (marketing, resource allocation, etc.) and then learn more deeply by applying this learning and critically reflecting on the learning processes and achievements (Talbot, 2017).

5. Embedding opportunities for the recognition of prior experiential learning, where relevant: allowing room in the curriculum for germane experiential learning also opens up the possibility of allowing students with considerable prior workplace experience and learning to claim credit for this and to deepen the learning by reflecting on it. Opportunity for this in traditional HE courses is often limited because work-based experiential learning is 'messy' (Raelin, 2008) and does not often map easily into predetermined module learning outcomes. However, incorporating shell modules such as work-based projects into the curriculum allows students to compile claims, where relevant, for their prior experiential learning and in doing so draw parallels and meaning from this and their more formal taught learning (Perrin \& Helyer, 2015).

6. Incorporation of assessment methods typical to NWBL programmes: this enables students to integrate artefacts and activities linked to the workplace as a legitimate means of demonstrating knowledge and capability. This could range from physical artefacts such as reports produced, or digital media created, through to assessment of presentations given to colleagues. These can be used towards the notional word count of modules and can allow learners to see the academic relevance and currency of workplace learning (Boud, 2000; Brodie \& Irving, 2007; Talbot, 2017).

\section{Case Studies of Real World Learning}

There are clearly a variety of ways in which 'leveraging' of NWBL approaches can occur, and we explore two case studies of where this has been happening in practice. Both of these are from universities with 
well-known NWBL frameworks and which have had sizeable numbers of students across a wide range of professional practice areas - and for many years. Staff involved in the facilitation of learning and assessment on them have built up considerable expertise in these fields and have developed genuine communities of academic practice (Major, Meakin, \& Perrin, 2011; Workman \& Garnett, 2009) that have helped foster and disseminate these practices-including internally at the universities concerned.

For over two decades the Centre for Work Related Studies (CWRS) at the University of Chester and what became the Institute for Work Based Learning (IWBL) at Middlesex University have been prominent exponents of NWBL in HE. Both have recruited significant numbers of students (typically with over a thousand part-time learners at any one time in each case) and have developed their NWBL expertise in a wide range of fields ranging from business and management through to health and education (Talbot et al., 2019). They have also disseminated their practice in developing pioneering approaches to experiential learning, negotiated learning and prior learning, among others (Garnett, Costley, \& Workman, 2009; Perrin, Weston, Thompson, \& Brodie, 2010; Talbot, 2017).

On a practical level—and driven by what could be called an ideological commitment to these types of HE learning-this has sometimes involved assisting other universities develop their own WBL frameworks. Latterly, this has also involved helping full-time undergraduate courses address the criticism that they are not producing 'job-ready' graduates and are not fully enabling students to claim academic reward for learning outside of traditional pedagogic environments. In each instance, the universities concerned have leveraged the skills and knowledge of their staff involved in NWBL to create alternative learning opportunities that can be embedded in full-time undergraduate curricula.

The first case study is from Chester, where the university developed the Work Based and Integrative Studies (WBIS) framework from 1998 onwards, housed and managed in the Centre for Work Related Studies. Over a period of years, CWRS worked closely with Chester Business School in the University to recalibrate the undergraduate offer for fulltime business and management students, including those in specific fields 
such as events management and tourism management. The following case study explores one of the main ways in which this has been approached.

\section{Case Study 1}

Leveraging NWBL in the Business School at the University of Chester (Connie Hancock, Head of Department for Enterprise, Leadership and Management, University of Chester, UK)

What follows is a discussion relating to applied research that was undertaken in the Business School to make provision for a partnership approach with business to support pragmatic assessment and formal acknowledgement of skills and learning acquisition gleaned through a 12-month undergraduate industrial placement for full-time students. This used many of the principles and approaches to learning, teaching and assessment developed within the University's NWBL framework.

There were 1.77 million undergraduate students, according to the Higher Education Statistics Agency, that were studying at UK institutions in 2017-2018, the majority of whom will amass significant debt towards securing a first rung on the career ladder. It is seen as an essential responsibility of higher education to prepare and equip these graduates for the workplace environment (CBI, 2009; Jackson \& Chapman, 2012). Nevertheless, embedding real world business skills into a business degree programme and immersing undergraduates in the authentic, dynamic world of business is acknowledged as providing a source of challenge in $\mathrm{HE}$. In response to this, institutions, practitioners and theorists alike see work-related placements and experiential, career-focused learning as fostering an informed approach to students' career planning and thinking (Morley, 2018; Wilson, 2012). To this end, business undergraduates at Chester, having completed the first two years of their degree programme, are now offered the opportunity to undertake an experiential learning placement year in industry, either in the UK or abroad.

The Business School has cultivated a range of relationships with external businesses and organisations with the objective of building sustainable links for mutually beneficial partnerships. Assessment of student placement activities drove dialogue with placement providers and led to 
opportunities for research into client and student needs and the development of an innovative approach to assessing experiential learning.

Sandwich placements and internships provide experiential interventions that make provision for the application of formal learning in a pragmatic, work-related environment (Edwards, 2014; Paglis Dwyer, 2013). The methodology through which this work-related experiential learning is assessed is a formal, academic system that lays greater emphasis on the formulating of the experience into what is an accepted traditional academic assignment that obscures the action orientation of the workplace. At Chester Business School, making provision for an assessment methodology that permits a more work-related, attitudinal, action- and behavioural-focused exploration of the student's performance as an employee in a work-based environment has been a challenge. It is this objective to align relevant assessment with student outputs in an industrial setting that prompted this research.

The interviewing by staff of 64 Chester Business School sandwich placement students and 58 workplace supervisors over the course of the industrial placement year 2017-2018 enabled the development of an innovative 'Action Portfolio' as the key point of assessment for experiential learning.

Student placements aid the acquisition of attributes, responses, behaviours, competencies and skills likely to significantly impact on student career insight (Edwards, 2014; Major, 2016). Placements secure links between institution and external agencies and organisations and support and build student competencies that aren't simply connected to career and employability development (Boud, Keogh, \& Walker, 1985; Edwards, 2014). Undergraduates returning after industrial placement at Chester displayed and referred to personal achievement systematically, with these typical responses:

I have delivered presentations and coordinated so many events and talks that nothing fazes me now. I can present to anyone and any number. I feel I have gained confidence for myself. (Student A)

I knew what was needed and I was confident that I could deliver. (Student B)

I know I can handle things now and I didn't know that before. (Student C) 
Whilst the development of such core skills are key in the development of work-ready graduates, the assessment of these outcomes is typically formal and inert in $\mathrm{HE}$, with students being required to demonstrate their academic articulation as opposed to work competence. A lack of scholarly dexterity in the formulation of an assessment does not necessarily correlate with the level of performance in the work-focused environment. The relevant assessment of experiential learning is vital in establishing work-related competencies, responsiveness in the workplace and the capacity to undertake appropriate actions and carry out key tasks, and as such it should not simply be associated with demonstrating academic prowess. Therein lay the challenge faced by Chester Business School. The data from our study indicated that high-performing interns were not necessarily reflecting their work-related competencies to a commensurate level in written format.

Following an analysis of the interviews and subsequent findings of the data gleaned from both students and workplace supervisor respondents, the Sandwich Placement Support Team set about designing a new assessment that would empower students to more effectively demonstrate high-level workplace experiential learning.

An Action Portfolio emerged from this study as a methodology of students being able to effectively communicate workplace experiential competencies. The portfolio consists of components established through research with placement providers, tutors and student interns and draws on approaches from the University's WBIS framework for part-time learners. This includes many of the nine key characteristics of NWBL listed above. In this way, comprehensive analysis of the data emanating from the study led to the establishment of a six-component Action Portfolio that is student and employer centred:

- A learning agreement consisting of ten learning objectives set after commencement of the placement via triangulated discussion between workplace supervisor, tutor and student intern. This sets the context for the mapping of the experiential learning journey; what skills and 
competencies the student has acquired and how they have been secured. Additions and amendments to the learning objectives may be recorded and discussed as the placement trajectory progresses. This component of the portfolio makes provision for planned and unplanned experiential learning and minimises the role of the tutor. Placement provider and student are best placed through an understanding of role and responsibility to draw up the learning objectives. The tutor's role is one of facilitation in this process.

- Two workplace observations of the intern, with two pre- and postobservational discussions carried out by the supporting tutor where the application of formal learning to a practical task is considered by the student. Both of these 'observations' are documented and included in the final portfolio as evidence of learning, with annotations by the student and, when appropriate and available, the workplace supervisor.

- Two feedback sessions with the workplace supervisor, with each of these discussions set into a report format that is either written by the supervisor or captured by the supporting tutor. This narrative may include any performance ratings, personal development reviews and skills audits, comments on progress or simply general comments and observations on the student's contribution to the organisation. These feedback sessions may take place at the time of the workplace observations.

- Delivery of a presentation within a 'mid-term conference', taking place, as the name suggests, halfway through their placement. The presentation is delivered to workplace representatives, Level 4 students who-the following year-will be applying for sandwich placements and current Level 5 students who will be currently making applications. The presentation deals with placement acquisition, organisation, and role, learning to date, negotiated learning objectives and how this learning will be utilised. Together with the question and answer phase, the presentation is recorded for portfolio submission and postevent critical reflection.

- A critically reflective commentary on practice that is underpinned with supporting academic references and evidence in the appendix. Supporting evidence of action, workplace output and competency level may be included with organisational approval. 
- Two curriculum vitae are required to form a component of the portfolio: one from the time of application of the placement and the other written at the time of placement completion. This inclusion, together with an annotated comparison of the two, emphasises the skills audit element helping to identify the 'transformation' taken place during the 12-month industrial placement.

The Action Portfolio components are mapped to employer needs in the business environment and research undertaken with students and tutors. This assessment strategy was deployed as a way of assessing students in the academic year 2018-2019 with significant success and resulted in an $18 \%$ increase in marks awarded to placement students. The external examiner acknowledged the results of this innovative assessment methodology, and the organisations continue to be involved in the partnership to empower interns to demonstrate experiential learning.

\section{Case Study 2}

Middlesex University 'Volunteering Module' (Ruth Miller, Director of WBL Programmes, School of Health and Education, Middlesex University, London)

The second case study is from Middlesex University and examines the creation of the University's volunteering module for full-time undergraduates. This utilises the negotiated and experiential learning approach specifically developed in the University's work-based learning framework for professional practitioners.

Opportunities for real world and work-based learning have a significant contribution to make in developing the employability and transferable skills that are now required outcomes for all graduates through the UK Teaching Excellence Framework (Department of Education, 2017). Although professional degrees such as nursing and social work already involve well-developed work placements, these are primarily for the enhancement and assessment of specific skills and competencies. More flexible work-based modules can provide an opportunity for students to develop (and have recognition for) wider personal, professional and transferable attributes valued by employers and society. 
During the recent revalidation of the negotiated work-based programmes for part-time professional practitioners within the School of Health and Education at Middlesex University, the work-based project and professional development modules were specifically validated so they could also be applied within full-time undergraduate degree programmes. This opportunity has been recently adopted in the newly validated BSc Mental Health Nursing degree, where a small 15-credit work-based project module has been adapted to offer an 'expansive learning' option called a 'work-based volunteering activity' during year 2 of the programme.

'Work-based volunteering activity' module learning outcomes are:

On completion of this module, the successful student will be able to:

- apply theoretical knowledge gained through volunteering activity to own professional practice and demonstrate an appreciation of the wider context of health and well-being.

This module will call for the successful student to demonstrate:

- effective engagement and communication with relevant stakeholders.

- reflection on activity outcomes and critical evaluation of own practice to inform professional development and action plan.

(Acknowledgement to Nicky Lambert, Director of Teaching and Learning Mental Health and Social Work, Middlesex University)

This option requires students to undertake-or draw on existing-volunteer work, negotiate specific activities via a learning agreement and critically discuss the learning gained to inform their own professional development. It provides a real world opportunity for students to develop the graduate attributes now required of all Middlesex University graduates, in particular being 'ethically informed and taking social responsibility', 'being culturally competent' and 'effective team players' (Middlesex University Graduate Attributes 2018/2019).

Whereas in their formal placements students are primarily required to apply their theoretical nursing knowledge to their developing practice, in this module they are extracting learning out of their practice and applying this back to their wider, developing, professional understanding. 
Many of the teaching and learning strategies developed to support professionals at work to reflect on and recognise their WBL (as in the nine key characteristic of NWBL above) are being applied to support these full-time undergraduates. In particular, critical reflection on their practice (both reflection in-action and on-action) has become key to maximising their learning. For example, asking structured questions about their own practice, both when things are not going well (Why was that an issue? What problem-solving techniques did I use to address that issue?) and when they are going well (Who did I have to engage with to make that happen? How did the way I communicate facilitate that exchange?). Although the depth and level of criticality will vary depending on the academic level required, this type of structured reflection is useful for all students undertaking practice learning.

The learning outcomes of the module are assessed through a professional portfolio requiring students to provide evidence of the activities they have engaged in as well as a critical reflection on how these activities are developing both their theoretical understanding and their broad professional skills. They are especially encouraged to consider their development within a wider social context and to provide an action plan of how they will develop these skills further. Rowe and Zegwaard (2017) stress the importance of appropriate assessment activities to support employability outcomes, and this type of portfolio assessment is flexible and relevant to students in a wide range of volunteering situations.

Other undergraduates can be encouraged to engage meaningfully in volunteering work by having their efforts recognised through such a module. Opportunities certainly exist within the University for student voice leaders (representatives) and students' union officers to develop graduate attributes and gain credit in this way.

\section{Conclusion}

This chapter has demonstrated that universities have incentives to work across perceived 'silos' and that there are clear advantages to drawing on the expertise developed through professional practice programmes of negotiated learning. This can enhance the overall learning experience for 
full-time undergraduate students striving for engagement that can in some ways reflect 'real world' issues, and who can then use this for professional development purposes. The challenge is often in building the type of internal culture that can enable this knowledge transfer to occur within the $\mathrm{HE}$ organisation. In particular, it requires academic managers and teaching staff to be receptive to 'non-traditional' forms of $\mathrm{HE}$ and to work openly with colleagues on this basis. This involves reappraisal very often of their own role as academics, challenging the status and practices associated with the narrow and didactic 'subject specialism' that has often been one of the hallmarks of HE.

Useful ways of enabling this in practice have included workshop sessions that have showcased the type of approaches used on WBIS at Chester and the WBL framework at Middlesex, together with opportunities for those who have only previously engaged with traditional programmes to get involved with shadowing staff who are specialists in the facilitation and assessment of NWBL (as a method rather than as a subject). These approaches are anticipated priorities for NWBL academic managers and would-be practitioners.

Our two case studies show that where such mindsets exist this can indeed be done_-and with positive results for students.

\section{References}

Bennis, W., \& O’Toole, J. (2005, May). How business schools lost their way. Harvard Business Review.

Boud, D. (2000). Sustainable assessment: Rethinking assessment for the learning society. Studies in Continuing Education, 22(2), 151-167. https://doi. org/10.1080/713695728

Boud, D., Keogh, R., \& Walker, D. (Eds.). (1985). Reflection: Turning experience into learning. Oxford: Routledge.

Boud, D., \& Symes, C. (2000). Learning for real: Work based education in universities. In C. Symes \& J. McIntyre (Eds.), Working knowledge: The new vocationalism and higher education. Berkshire: SRHE/OUP.

Brodie, P., \& Irving, K. (2007). Assessment in work-based learning: Investigating a pedagogical approach to enhance student learning. Assessment 
\& Evaluation in Higher Education, 32(1), 11-19. https://doi.org/10.1080/ 02602930600848218

Brookfield, S. (1991). Developing critical thinkers: Challenging adults to explore alternative ways of thinking and acting. San Francisco: Jossey-Bass.

Confederation of British Industry. (2009). Future fit: Preparing graduates for the world of work. CBI.

Department of Education. (2017). Teaching excellence and student outcomes framework specification. Retrieved from https://assets.publishing.service.gov. uk/government/uploads/system/uploads/attachment_data/file/658490/ Teaching_Excellence_and_Student_Outcomes_Framework_ Specification.pdf

Dewey, J. (1897). My pedagogic creed. The School Journal, 54(3), 77-80.

Edwards, M. (2014). The impact of placements on students' self-efficacy. Higher Education, Skills and Work-Based Learning, 4(3), 228-241. https://doi. org/10.1108/HESWBL-05-2014-0015

Eraut, M. (2010). Knowledge, working practices, and learning. In S. Billett (Ed.), Learning Through Practice, professional and practice-based learning 1. Dordrecht: Springer.

Garnett, J., Comerford, A., \& Webb, N. (2001). Working with partners to promote intellectual capital. In D. Boud \& N. Solomon (Eds.), Work based learning: A new higher education? Buckingham: SRHE/OUP.

Garnett, J., Costley, C., \& Workman, B. (Eds.). (2009). Work based learning: Journeys to the Core of higher education. London: Middlesex University Press.

Gibbons, M., Limoges, C., Notwotny, H., Schwartzman, S., Scott, P., \& Trow, M. (1994). The new production of knowledge: The dynamics of science and research in contemporary societies. London: Sage.

Helyer, R., \& Lee, D. (2014). The role of work experience in the future employability of higher education graduates. Higher Education Quarterly, 68(3), 348-372. https://doi.org/10.1111/hequ.12055

Jackson, D. (2013). Business graduate employability-Where are we going wrong? Higher Education Research \& Development, 32(5), 776-790. https:// doi.org/10.1080/07294360.2012.709832

Jackson, D., \& Chapman, E. (2012). Non-technical competencies in undergraduate business degree programs: Australian and UK perspectives. Studies in Higher Education, 37(5), 541-567. https://doi.org/10.1080/0307507 9.2010.527935

Knowles, M. (1986). Using learning contracts: Practical approaches to Individualising and structuring learning. San Francisco: Jossey Bass. 
Little, B., \& Brennan, J. (1996). A Review of Work Based Learning in Higher Education. Sheffield: Department for Education and Employment.

Major, D. (2016). Models of work-based learning, examples and reflections. Journal of Work-Applied Management, 8(1), 17-28. ISSN: 2205-2062.

Major, D., Meakin, D., \& Perrin, D. (2011). Building the capacity of higher education to deliver programmes of work-based learning. Higher Education, Skills and Work-Based Learning, 1(2), 118-127. ISSN: 2042-3896.

Middlesex University. (2017). Middlesex graduate attributes 2017/18. Section 3 learning quality enhancement handbook. Retrieved from https://www.mdx. ac.uk/about-us/policies/academic-quality/handbook/lqe-handbooksection-3

Morley, D. (Ed.). (2018). Enhancing employability in higher education through work based learning. London: Palgrave Macmillan.

Nicolescu, B. (2002). Manifesto of transdisciplinarity. New York: State University of New York Press.

Paglis Dwyer, L. (2013). A review of managerial skills training in the classroom. Journal of Management Education, 37, 472-498. https://doi. org/10.1177/1052562912436516

Perrin, D., \& Helyer, R. (2015). Make your learning count: Recognition of prior learning. In R. Helyer (Ed.), The work based learning student handbook. Basingstoke: Macmillan.

Perrin, D., Weston, P., Thompson, P., \& Brodie, P. (2010). Facilitating employer engagement through negotiated work based learning. Bristol: HEFCE/DWP.

Raelin, J. (2008). Work-based learning: Bridging knowledge and action in the workplace. San Francisco: Jossey Bass.

Rowe, A., \& Zegwaard, K. (2017). Developing graduate employability skills and attributes through work integrated learning. Asia-Pacific Journal of Cooperative Education, 18(2), 87-99.

Stephenson, J., \& Laycock, M. (Eds.). (1993). Using learning contracts in higher education. London: Kogan Page.

Stephenson, J., \& Saxton, J. (2005). Using the internet to gain personalized degrees from learning through work: Some experience from Ufi. Industry and Higher Education, 19(3), 249-258.

Talbot, J. (2017). Curriculum design for the post-industrial society: The facilitation of individually negotiated higher education in work based learning shell frameworks in the United Kingdom. In R. V. Nata (Ed.), Progress in education (Vol. 44, pp. 127-161). New York, NY: Nova Science Publishers. 
Talbot, J., Perrin, D., \& Meakin, R. (2019). What does it take for flexible learning to survive? A UK case study. In Higher education, skills and work-based learning, 10 (1). https://doi.org/10.1108/HESWBL-02-2019-0022

Wall, T., \& Perrin, D. (2015). A Zizekian gaze at education. London: Springer.

Willis, K. (2008). Framework for work-based learning. In F. Tallantyre (Ed.), Work based learning, workforce development: Connections, frameworks and processes. York: Higher Education Academy.

Wilson, T. (2012). A review of business-University collaboration. London, Department for Business, Innovation \& Skills.

Workman, B., \& Garnett, J. (2009). The development and implementation of work based learning at Middlesex University. In J. Garnett, C. Costley, \& B. Workman (Eds.), Work based learning: Journeys to the core of higher education. London: Middlesex University.

Open Access This chapter is licensed under the terms of the Creative Commons Attribution 4.0 International License (http://creativecommons.org/licenses/ by/4.0/), which permits use, sharing, adaptation, distribution and reproduction in any medium or format, as long as you give appropriate credit to the original author(s) and the source, provide a link to the Creative Commons licence and indicate if changes were made.

The images or other third party material in this chapter are included in the chapter's Creative Commons licence, unless indicated otherwise in a credit line to the material. If material is not included in the chapter's Creative Commons licence and your intended use is not permitted by statutory regulation or exceeds the permitted use, you will need to obtain permission directly from the copyright holder.

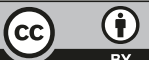

